\title{
Ultrathin Alumina Membranes for Surface Nanopatterning in Fabricating Quantum-Sized Nanodots
}

\author{
Minghong Wu, Liaoyong Wen, Yong Lei, ${ }^{*}$ Stefan Ostendorp, Kai Chen, and \\ Gerhard Wilde
}

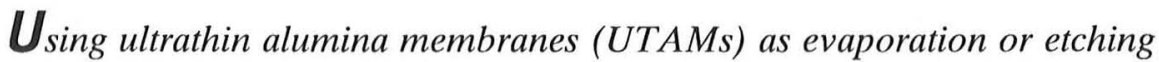
masks large-scale ordered arrays of surface nanostructures can be synthesized on substrates. However, it is a challenge for this technique to synthesize quantum-sized surface structures. Here an innovative approach to prepare UTAMs with regularly arrayed pores in the quantum size range is reported. This new approach is based on a well-controlled pore-opening process and a modulated anodization process. Using UTAMs with quantum-sized pores for the surface patterning process, ordered arrays of quantum dots are synthesized on silicon substrates. This is the first time in realizing large-scale regularly arrayed surface structures in the quantum size range using the UTAM technique, which is an important breakthrough in the field of surface nanopatterning.
\end{abstract}

Keywords:

- alumina membranes

- nanopatterning

- quantum dots

- template synthesis

\section{Introduction}

As a well known nanotemplate, anodic alumina mem branes have been widely used in fabricating different one dimensional (1D) nanostructures, ${ }^{[1-5]}$ especially after the large improvement in the pore regularity of alumina membranes based on a two step anodization process. ${ }^{[6,7]}$ The synthesis of ordered arrays of $1 \mathrm{D}$ nanostructures benefits from the regularly arrayed pores of alumina membranes with monodisperse diameters. Recently, using ultrathin alumina membranes (UTAMs) as the evaporation or etching masks, large scale ordered arrays of surface nanostructures (e.g., nanodots and nanoholes) have been successfully synthesized on the surface of substrates (mainly Si wafers)..$^{[7-18]}$ This UTAM surface nanopatterning technique possesses some attractive

[*] Prof. Y. Lei, Dr. W. M. Wu, L. Y. Wen, K. Chen Institute of Nanochemistry and Nanobiology School of Environmental and Chemical Engineering Shanghai University, Shanghai 201800 (P. R. China) E mail: yong.lei@uni muenster.de

Prof. Y. Lei, S. Ostendorp, Prof. G. Wilde Institute of Materials Physics and Center for Nanotechnology University of Munster, Munster 48149 (Germany)

Supporting Information is available on the WWW under http:// www.small journal.com or from the author.

DOI: $10.1002 / \mathrm{smll} .200902038$ $\operatorname{advantages}^{|8|}$ such as large pattern area $\left(>1 \mathrm{~cm}^{2}\right)$, high throughput, ultrahigh density $\left(10^{10} 10^{12} \mathrm{~cm}^{-2}\right)$ of the surface nanostructures, and low equipment costs.

There are two challenging technical points preventing the existing UTAM patterning and template directed processes from synthesizing regularly arrayed nanostructures in the quantum size range (below $1020 \mathrm{~nm}$ ). First, although the minimum pore diameter of alumina membranes is about $10 \mathrm{~nm}$, the arrangement regularity and monodispersity of pores are poor when the pore diameter is smaller than $20 \mathrm{~nm}$. This largely limits the investigation of the quantum confinement effect based on the template prepared ordered arrays of nanostruc tures with monodisperse diameter. Second, the aspect ratio of the pores of UTAMs that are suitable for use in the surface nanopatterning process should be smaller than $10,{ }^{|8|}$ for example, the thickness of a UTAM with $20 \mathrm{~nm}$ diameter pores should be smaller than $200 \mathrm{~nm}$. However, when UTAMs are prepared using sulfuric acid solutions (the solutions to prepare membranes with smaller pores, e.g., $20 \mathrm{~nm}$ ), the large growth rate of alumina layers in the sulfuric acid solutions makes it hard to obtain UTAMs with thicknesses smaller than $200 \mathrm{~nm}$ (aspect ratio is 10 for $20 \mathrm{~nm}$ diameter pores). This is the reason why so far the anodization process of UTAMs is limited to oxalic acid solutions, ${ }^{[7-9]}$ giving UTAMs with pores larger than $30 \mathrm{~nm}$. And it is difficult to obtain small pore UTAMs (with pore diameters smaller than $20 \mathrm{~nm}$ ) that are suitable to be used for the surface patterning process. This prevents the fabrication of 
quantum sized surface structures using the UTAM patterning technique. Thus one of the most attractive features of nanomaterials, the quantum confinement effect, is missing in the UTAM surface nanopatterning process.

In this Full Paper, we show a new route to prepare UTAMs with regularly arrayed pores in the quantum size range and consequently to synthesize ordered arrays of quantum dots. First, modulators were introduced into the anodization solutions, which significantly decreased the anodization current and the growth rate of UTAMs. Based on this low growth rate, UTAMs with a thickness of about $80 \mathrm{~nm}$ were prepared, and regular arrays of nanodots with diameters of about $20 \mathrm{~nm}$ were fabricated using these UTAMs. More importantly, we proposed a well controlled pore opening process of UTAMs. Using the process, the diameter of pore openings of UTAMs is well controlled in the range of 5 to $27 \mathrm{~nm}$. Ordered arrays of surface nanodots within a similar size range can be fabricated using these UTAMs. Here we show the fabrication of regular nanodots with an average diameter of about $17 \mathrm{~nm}$. This is the first time in realizing regularly arrayed pores and surface nanostructures in the quantum size range using the UTAM surface patterning and template directed technique.

\section{Results and Discussion}

Our UTAM surface nanopatterning process starts with a two step anodization process (Figure 1 ) using $0.3 \mathrm{M}$ sulfuric acid solutions with mixed solvents of water and a modulator (glycol). The volume ratio of glycol to water is 3:2. Due to the low freezing point of glycol, the anodization process can be carried out at an extremely low temperature of $20^{\circ} \mathrm{C}$ without a stirring of electrolytes. The anodization current is much smaller than that of the anodization process using $0.3 \mathrm{M}$ sulfuric acid solutions at $0^{\circ} \mathrm{C}$, resulting in a much lower growth rate of UTAMs compared to that of the UTAMs prepared using non modulated sulfuric acid solution. Due to this much lower growth rate, a UTAM with a thickness of about $80 \mathrm{~nm}$ was prepared on a Si substrate (Figure'1i). This UTAM was synthesized using a short anodization time of $5.5 \mathrm{~min}$ under $25 \mathrm{~V}$. The $80 \mathrm{~nm}$ thickness of the UTAM suggests a growth rate of about $15 \mathrm{~nm} \mathrm{~min}^{-1}$, which is just about $1 / 10$ of the growth rate of about $150 \mathrm{~nm} \mathrm{~min}^{-1}$ of the UTAMs prepared using $0.3 \mathrm{M} \mathrm{non}$ modulated sulfuric acid solution at $0^{\circ} \mathrm{C}$. Using this UATM, ordered arrays of Au nanodots with diameters of about $20 \mathrm{~nm}$ were prepared (Figure 1i).

The voltage "breakdown" point (or "burning" point) of the anodic alumina layer prepared using non modulated sulfuric acid solutions is about $2527 \mathrm{~V}$. This breakdown anodization is caused by the high reaction heat of a relatively high anodization current. The pore cell size (interpore distance) of the alumina membranes prepared under $27 \mathrm{~V}$ using sulfuric acid solution is about $65 \mathrm{~nm}$. Moreover, the smallest cell size of the self ordering pores of the alumina membranes prepared using oxalic acid solution is about $100 \mathrm{~nm}$. Therefore, it is hard to prepare alumina membranes with a self ordering range (cell size) in the range of $65100 \mathrm{~nm}$ using conventional non modulated anodization processes.

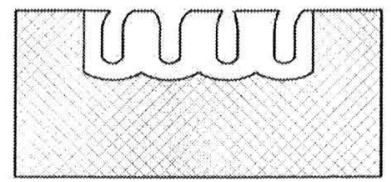

(a) First Anodization

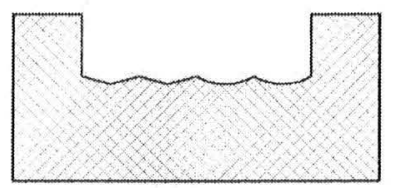

(b) Removal of Alumina

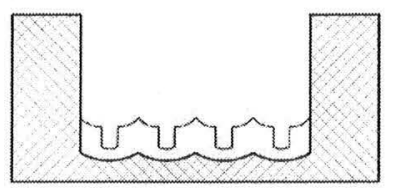

(c) Second Anodization

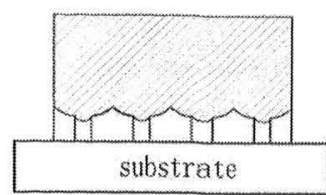

(e) Pore-Widening and mount onto Substrate

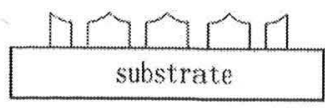

(f) Removal of PMMA Layer

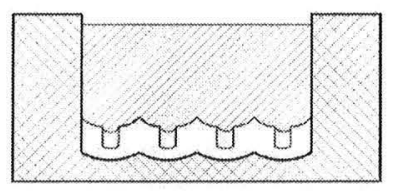

(d) PMMA Layer \& Removal of Al and Barrier Layer

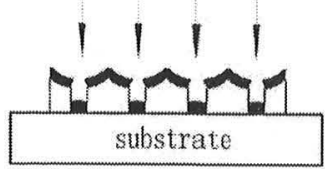

(g) Deposition of Nanoparticle

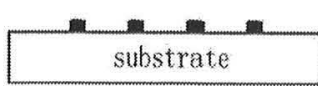

(h) Removal of Alumina Mask

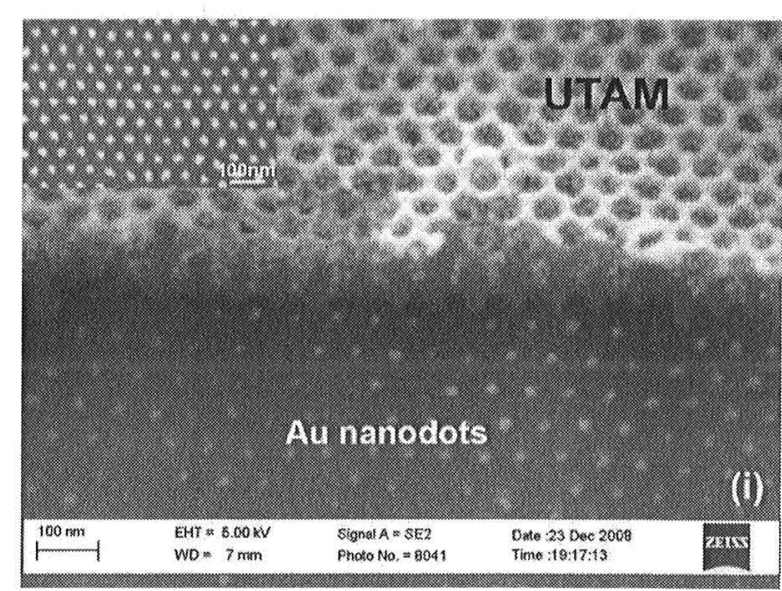

Figure 1. Schematic outline of the fabrication of ultrathin alumina masks and ordered nanodot arrays ( $\mathrm{a} h$ ) and an SEM image (i) of UTAM prepared Au nanodot arrays with part of the UTAM remaining (anodized in a $0.3 \mathrm{M}$ modulated $\mathrm{H}_{2} \mathrm{SO}_{4}$ solution, glycol:water 3:2). The thickness of the UTAM is about $80 \mathrm{~nm}$ and the diameter of the Au nanodots is about $20 \mathrm{~nm}$. The inset in (i) is the top view of the nanodots.

In our experiments, by adding a modulator in the anodization solution, the extremely low anodization current and temperature largely suppress the breakdown effect and enable a uniform growth of oxide films at a higher voltage. Using glycol as the modulator, it is found that the anodization voltage can be extended from $2527 \mathrm{~V}$ to $40 \mathrm{~V}$ at $4{ }^{\circ} \mathrm{C}$ in a $0.3 \mathrm{M}$ modulated sulfuric acid solution without a special cool system and vigorous stirring, which means that the breakdown voltage could be even higher than $40 \mathrm{~V}$ (e.g., using $20^{\circ} \mathrm{C}$ anodization 


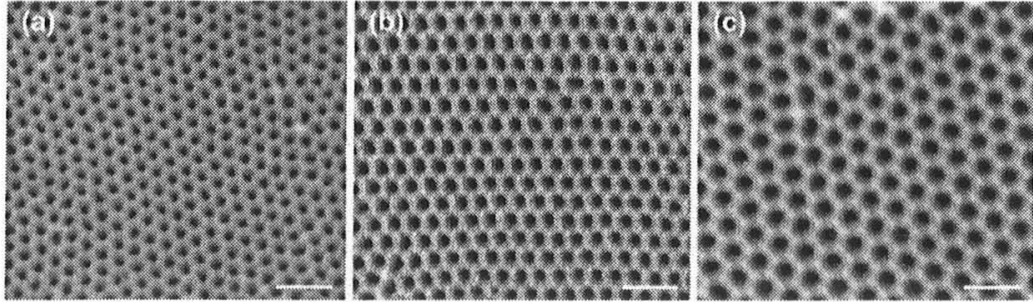

Figure 2. SEM images of UTAMs (top view) prepared in a $0.3 \mathrm{M}$ modulated $\mathrm{H}_{2} \mathrm{SO}_{4}$ solution (glycol:water 3:2) under anodization voltages of a) $25 \mathrm{~V}$, b) $29 \mathrm{~V}$, and c) $40 \mathrm{~V}$. The scale bars in these figures are all $200 \mathrm{~nm}$. The cell sizes of the pores are about a) $60 \mathrm{~nm}$, b) $70 \mathrm{~nm}$, and c) $95 \mathrm{~nm}$, respectively.

temperature). We prepared a set of five UTAMs in a $0.3 \mathrm{M}$ modulated sulfuric acid solution (the volume ratio of glycol to water was 3:2) at $4{ }^{\circ} \mathrm{C}$ under different anodization voltages of $25,29,33,37$, and $40 \mathrm{~V}$. Figure 2 shows the regular pore arrays of the UTAMs prepared under 25,29 , and $40 \mathrm{~V}$. It can be seen that the pore diameter and cell size of alumina membranes increase with the increase of the anodization voltage. There is a linear relationship between the UTAM cell size and the anodization voltage (Figure 3), and the cell size can be adjusted in the range of about $60 \mathrm{~nm}(25 \mathrm{~V})$ to $95 \mathrm{~nm}(40 \mathrm{~V})$. Moreover, UTAMs prepared using the different anodization voltages in the range of $2540 \mathrm{~V}$ have regular pore arrangement (Figure 2).

In the conventional "mild anodization" processes ${ }^{[19-21]}$ and an emerging "hard anodization" process, ${ }^{[22]}$ self ordered arrays of alumina pores can be obtained within the following ranges: 1) sulfuric acid at $1925 \mathrm{~V}$ for a cell size of 50 $65 \mathrm{~nm},{ }^{[19,20]}$ 2) oxalic acid at $40 \mathrm{~V}$ for a cell size of $100 \mathrm{~nm},{ }^{[20]}$ 3) sulfuric acid at $4070 \mathrm{~V}$ for a cell size of $95140 \mathrm{~nm},{ }^{[21]}$ 4) oxalic acid at $120150 \mathrm{~V}$ for a cell size of $220300 \mathrm{~nm},{ }^{[22]}$ and 5) phosphoric acid at $160195 \mathrm{~V}$ for a cell size of $405500 \mathrm{~nm} \cdot{ }^{[23]}$ In our work, the new self ordering range of the cell size in the range of $6095 \mathrm{~nm}$ fills in the gap of the self ordering spectrum of anodic alumina membranes.

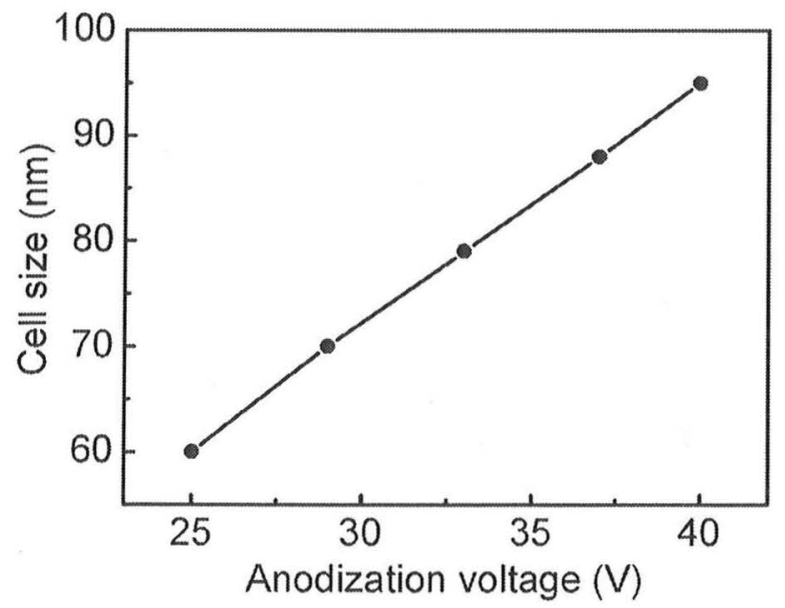

Figure 3. The dependence of the cell size (interpore distance) of UTAMs on the anodization voltage. The UTAMs were prepared in a $0.3 \mathrm{M} \mathrm{H}_{2} \mathrm{SO}_{4}$ solution (glycol:water $3: 2$ ) at $4{ }^{\circ} \mathrm{C}$. The diameters of the UTAMs are (under different anodization voltages): $60 \mathrm{~nm}, 25 \mathrm{~V} ; 70 \mathrm{~nm}, 29 \mathrm{~V} ; 78 \mathrm{~nm}$, $33 \mathrm{~V} ; 88 \mathrm{~nm}, 37 \mathrm{~V} ; 95 \mathrm{~nm}, 40 \mathrm{~V}$.
To obtain regular pores of UTAMs and hence UTAM prepared nanostructures within the quantum size range, a well controlled pore opening process of the barrier layer of UTAMs was introduced in this work (Figure 4). There is an alumina barrier layer between the pore bottom and the aluminum foil of the as prepared anodic alumina membranes. This thin non porous barrier layer has a hemispherical and scalloped geometry (Supporting Information, Figure S1). Using acidic etch ing solutions, the barrier layer can be thinned and finally removed.

The UTAMs used in our experiments for the pore opening process were prepared using $0.3 \mathrm{M}$ modulated sulfuric acid solution (glycol:water $=3: 2$ ) under $25 \mathrm{~V}$ at $4{ }^{\circ} \mathrm{C}$. The cell size, pore diameter, and the barrier layer thickness of the as prepared UTAMs are about 60,20 , and $20 \mathrm{~nm}$, respectively. The pore opening process was carried out using a $5 \mathrm{wt} \% \mathrm{H}_{3} \mathrm{PO}_{4}$ solution at $30^{\circ} \mathrm{C}$. Before the etching, UTAMs were covered by a protecting PMMA layer on the top so that the $\mathrm{H}_{3} \mathrm{PO}_{4}$ solution can only etch on the bottom surface of the barrier layer. Figure 4 shows the bottom surface of UTAMs in the pore opening process (for details see Figure S2 in the Supporting Information). The microstructure of the barrier layer before etching is shown in Figures $4 a$ and S2a. It is found that there is no pore opening with an etching time of $8 \mathrm{~min}$ (Figure S2b). The pores start to open on the top of the hemisphere with an etching time of about $13 \mathrm{~min}$, and the diameter of the pore openings is about $5 \mathrm{~nm}$ with an etching time of $15 \mathrm{~min}$ (Figures $4 \mathrm{~b}$ and S2c). The diameter of the pore openings increases with the etching time, resulting in pore openings of about $10 \mathrm{~nm}$ with $18 \mathrm{~min}$ (Figures $4 \mathrm{c}$ and S2d), $17 \mathrm{~nm}$ with $24 \mathrm{~min}$ (Figures $4 \mathrm{~d}$ and S2e), $22 \mathrm{~nm}$ with $30 \mathrm{~min}$ (Figure S2f), and $27 \mathrm{~nm}$ with $40 \mathrm{~min}$ (Figure $\mathrm{S} 2 \mathrm{~g}$ ). The dependence of the diameter of the pore openings on the etching time is shown in Figure S3. The diameter of the pore openings can be controlled based on the adjustment of the etching time.

Figure 4 also shows the etching mechanism of the pore opening process (for details see Figure S4 in the Supporting Information). As shown in Figures $4 \mathrm{a}$ and S4a, due to the reaction of the acid solution with the alumina on the surface of barrier layer, many acid ions are consumed near the surface of barrier layer and it needs ionic compensation from the bulk solution so as to keep the ionic concentration. However, the ionic compensation should be relatively easier at the top (center) of the hemispherical barrier layer than that at the bottom (the joint points of the two adjacent barrier layers). Thus the ionic concentration at the top of the hemispherical barrier layer is higher than that at the bottom, resulting in a faster etching rate at the top than at the bottom of barrier layer (as indicated by the arrows in Figures 4a and S4a; the etching rate is proportional to the length of arrows). After about $13 \mathrm{~min}$ of etching, the center point of the hemispherical barrier layer starts to open, while the other parts of the barrier layer keep closed (Figure S4c). With further etching, the pore opening becomes larger. The pore opening size increases with the etching time (Figures $\mathrm{S} 4 \mathrm{~d}$ to $\mathrm{S} 4 \mathrm{~h}$ ). Meanwhile, the acid solution 


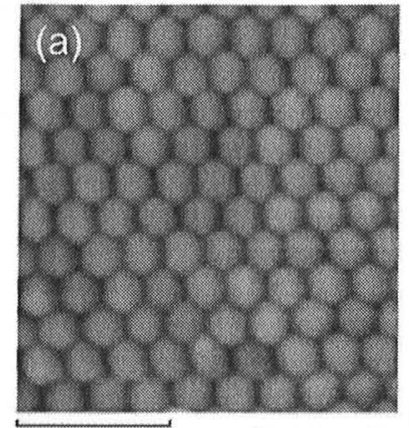

$200.00 \mathrm{~nm}$

$50000 \times 500.00 \mathrm{~nm}$
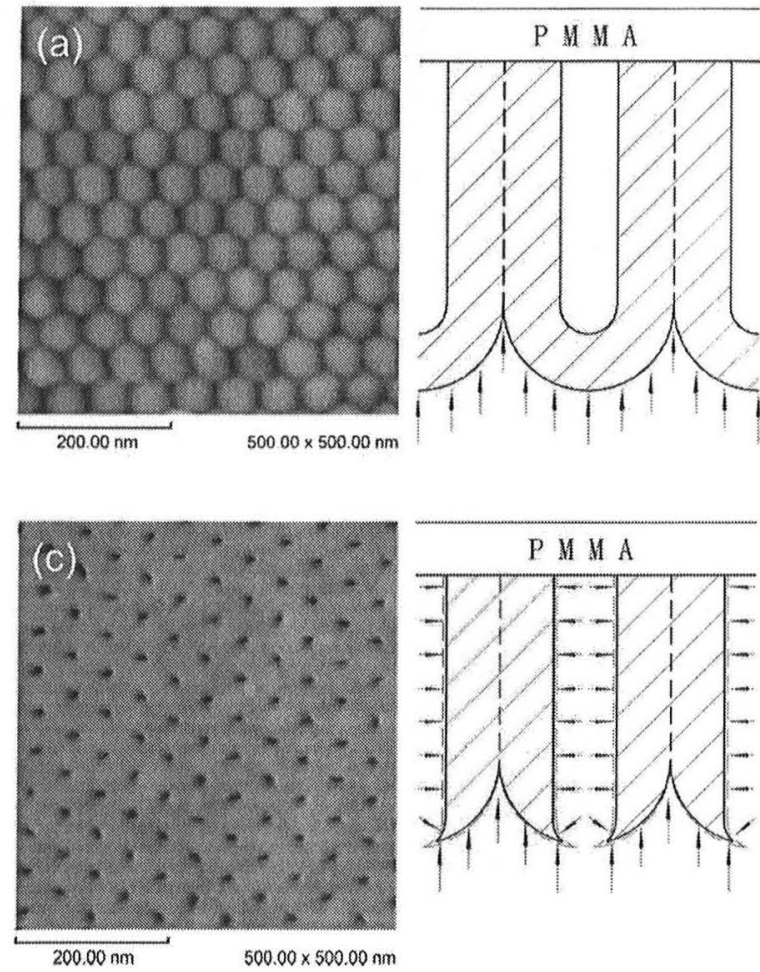
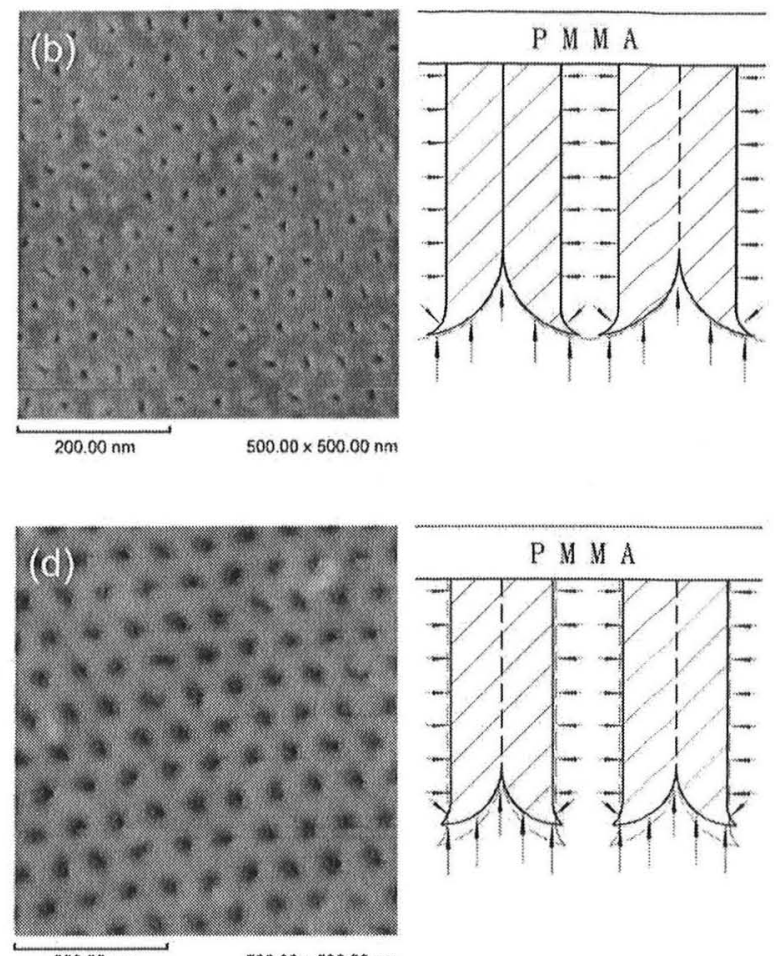

$200.00 \mathrm{~nm} \quad 500.00 \times 500.00 \mathrm{~nm}$

Figure 4. AFM images of the bottom surfaces of UTAMs (prepared in $0.3 \mathrm{M} \mathrm{H}_{2} \mathrm{SO}_{4}$ solution, glycol:water 3:2) with different etching times of $5 \mathrm{wt} \% \mathrm{H}_{3} \mathrm{PO}_{4}$ solution. a) As prepared (0 min), b) $\left.15 \mathrm{~min}, \mathrm{c}\right) 18 \mathrm{~min}$, and d) $24 \mathrm{~min}$. The size of the pore opening is about $5 \mathrm{~nm}(\mathrm{~b}), 10 \mathrm{~nm}$ (c), and $17 \mathrm{~nm}$ (d). The right parts of each figure are the schematic outline of the pore opening process (cross sectional view), which show the etching mechanism. The arrows show the etching directions and the lengths of the arrows are proportional to the etching rate.

goes into the pores via the pore openings and etches the pore walls, that is, there is a pore widening process accompanying the pore opening process. The double sided etching on the barrier layer (Figures S4d to S4g) flattens the hemispherical barrier layer, and finally an almost flat bottom surface of the UTAM is obtained (Figure S4h).

UTAMs with pore openings smaller than $20 \mathrm{~nm}$ can be used to fabricate ordered arrays of quantum dots. Using an UTAM with pore openings of about $17 \mathrm{~nm}$ diameter (as shown in Figure $4 \mathrm{~d})$, large scale $\left(\approx 2 \mathrm{~cm}^{2}\right)$ ordered arrays of Au quantum dots were prepared on a Si substrate (Figure 5a). Based on the histogram and its Gaussian fit curve (Figure 5b) of the measured diameters of the Au nanodots, the average diameter of the nanodots is about $17.02 \mathrm{~nm}$. This advances the capability of the UTAM patterning technique for the fabrication of quantum sized surface nanostructures.
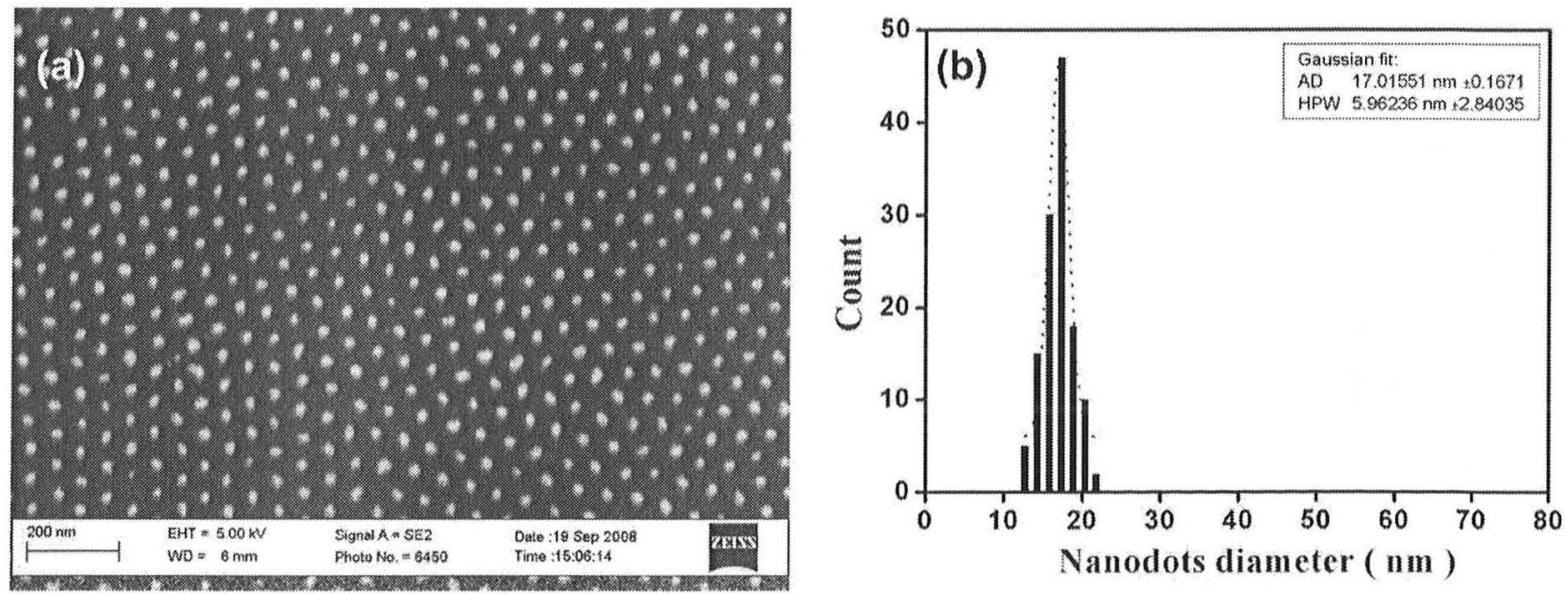

Figure 5. a) SEM image (top view) of ordered arrays of Au nanodots (on a Si wafer) prepared using an UTAM with 24 min pore opening (same as the UTAM in Figure 3e). b) Histogram and its Gaussian fit curve (dashed line) of the measured diameters of all the Au nanodots in (a). The AD (17.02 nm) and HPW $(5.96 \mathrm{~nm})$ in the figures are the average diameter and half peak width of the Gaussian fit curve, respectively. 


\section{Conclusion}

In summary, we report here a combined synthesizing method of UTAMs based on a well controlled pore opening process and a modulated anodization process. Using the method, UTAMs with regularly arrayed pore openings in the quantum size range and ordered arrays of quantum dots were realized, which is an important breakthrough in surface nanopatterning and the template directed technique. The large scale ordered arrays of quantum sized surface structures are promising candidate structures for new types of optoelectronic and display devices on the basis of the quantum confinement effect.

\section{Experimental Section}

Fabrication of UTAMs and Nanodot Arrays: UTAMs were prepared using a two-step anodization process. High-purity $(99.999 \%)$ aluminum foils with a thickness of about $0.22 \mathrm{~mm}$ were used. Before the anodization process, the Al foils were degreased with acetone and annealed at $400^{\circ} \mathrm{C}$ for $4 \mathrm{~h}$, followed by an electropolishing process in a mixture solution of perchloric acid and ethanol $(1: 9 \mathrm{v} / \mathrm{v})$ at a constant current density $\left(750 \mathrm{~mA} \mathrm{~cm}^{-2}\right)$ for $2 \mathrm{~min}$. The anodization solutions are sulfuric acid solution $(0.3 \mathrm{M})$ with mixed solvents of water and glycol $(3: 2 \mathrm{v} / \mathrm{v})$. The pretreated $\mathrm{Al}$ foils were anodized for $12 \mathrm{~h}$ under constant voltage (Figure 1a). Then the alumina layer was removed in a mixture of $\mathrm{H}_{3} \mathrm{PO}_{4}(6 \mathrm{wt} \%)$ and $\mathrm{H}_{2} \mathrm{CrO}_{4}(1.8 \mathrm{wt} \%)$ at $60^{\circ} \mathrm{C}$ for $12 \mathrm{~h}$ (Figure $1 \mathrm{~b}$ ). The specimen was anodized again for a short time period using the same solution and anodization voltage as those of the first anodization process, and finally a UTAM was obtained (Figure 1c). Due to the low freezing point of the modulator, the anodization process can be carried out at a low temperature of $20^{\circ} \mathrm{C}$ without a stirring of the electrolytes. Thus the anodization current is much smaller than that of the anodization process using $0.3 \mathrm{M}$ nonmodulated sulfuric acid solution at $0{ }^{\circ} \mathrm{C}$. The time for the second anodization is in the range of $5-15$ minutes depending on the required thickness of UTAM. The anodization voltage can be adjusted in a range of $25-40 \mathrm{~V}$ (in the meantime, the voltage of the first and second anodization process is kept at the same value), resulting in UTAMs with different structural parameters, including the pore diameter and cell size.

After the fabrication of an UTAM on an Al foil (Figure 1a-c), a PMMA layer was spin-coated on the top of the UTAM using a $6 \%$ $\mathrm{PMMA} /$ chlorobenzene solution with a heat-treatment process at $120^{\circ} \mathrm{C}$ for 25 mins (Figure $1 \mathrm{~d}$ ). After that, the Al layer on the back was removed in a mixture of $\mathrm{CuCl}_{2}$ and $\mathrm{HCl}$. The removal of the barrier layer was carried out in a $\mathrm{H}_{3} \mathrm{PO}_{4}$ solution ( 5 wt\%), forming an UTAM with a PMMA layer on the top. Then the UTAM/PMMA was mounted on a Si wafer (Figure 1e). The PMMA layer was removed using acetone (Figure $1 \mathrm{f}$ ), and the UTAM was finally attached on the substrate with acetone. Au nanodot arrays were thermally evaporated using an Edwards Auto 306 Evaporator (Figure 1g). After the preparation of Au nanodot arrays, the UTAM was etched away using a $\mathrm{H}_{3} \mathrm{PO}_{4}$ solution (5 wt\%), leaving highly ordered $\mathrm{Au}$ nanodot arrays on the surface of the substrate
(Figure $1 \mathrm{~h}$ ). The area of the UTAM (and the Au nanodot array) is about $2 \mathrm{~cm}^{2}$ with our current anodization setup and can be as large as several tens of square centimeters with a modified setup.

Characterization: The structure of the UTAMs and nanodot arrays was observed using a scanning electron microscope [(SEM), Zeiss 1540 EsB CrossBeam] and an atomic force microscope (Shimadzu SPM-9600, phase operation mode).

\section{Acknowledgements}

We thank S. W. Zhang for the drawing preparation. This was a collaborative work between the University of Münster and Shanghai University. It was financially supported by the European Research Council Starting Grant (ThreeDSurface), Volkswagen Stiftung, Deutsche Forschungsgemeinschaft (TRR61), Shanghai Dong-Fang Scholarship, Shanghai Leading Academic Disciplines (S30109), and National Natural Science Foundation of China (40830744).

[1] C. R. Martin, Chem. Mater. 1996, 8, 1739.

[2] D. Routkevitch, T. Bigioni, M. Moskovits, J. M. Xu, J. Phys. Chem. 1996, 100, 14037.

[3] J. Li, C. Papadopoulos, J. M. Xu, Nature 2000, 402, 253.

[4] Y. Lei, L. D. Zhang, G. W. Meng, G. H. Li, X. Y. Zhang, C. H. Liang, W. Chen, S. X. Wang, Appl. Phys. Lett. 2001, 78, 1125.

[5] M. Steinhart, J. H. Wendorff, A. Greiner, R. B. Wehrspohn, K. Nielsch, J. Schilling, J. Choi, U. Gosele, Science 2002, 296, 1997.

[6] H. Masuda, K. Fukuda, Science 1995, 268, 1466.

[7] H. Masuda, M. Satoh, Jpn. J. Appl. Phys. 1996, 35, L126.

[8] Y. Lei, W. P. Cai, G. Wilde, Prog. Mater. Sci. 2007, 52, 465.

[9] H. Masuda, K. Yasui, K. Nishio, Adv. Mater. 2000, 12, 1031.

[10] J. Liang, S. K. Hong, N. Kouklin, R. Beresford, J. M. Xu, Appl. Phys. Lett. 2003, 83, 1752.

[11] T. Ono, C. Konoma, H. Miyashita, Y. Kanamori, M. Esashi, Jpn. J. Appl. Phys. 2003, 42, 3867.

[12] Y. Lei, K. S. Yeong, J. T. L. Thong, W. K. Chim, Chem. Mater. 2004, $16,2757$.

[13] M. S. Sander, M. J. Cote, W. Gu, B. M. Kile, C. P. Tripp, Adv. Mater. 2004, 16, 2052.

[14] Y. Lei, W. K. Chim, H. P. Sun, G. Wilde, Appl. Phys. Lett. 2005, 86, 103106.

[15] Y. Lei, W. K. Chim, J. Am. Chem. Soc. 2005, 127, 1487.

[16] I. H. Park, J. W. Lee, S. H. Jeong, C. W. Chung, Electrochem. Solid. State. Lett. 2005, 8, C117.

[17] Y. Lei, W. K. Chim, Chem. Mater. 2005, 17, 580.

[18] S. G. Cloutier, R. S. Guico, J. M. Xu, Appl. Phys. Lett. 2005, 87, 222104.

[19] H. Masuda, F. Hasegwa, S. Ono, J. Electrochem. Soc. 1997, 144, L127.

[20] A. P. Li, F. Mueller, A. Birner, K. Nielsch, U. Gosele, J. Appl. Phys. 1998, 84, 6023.

[21] S. Z. Chu, K. Wada, S. Inoue, M. Isogai, A. Yasumori, Adv. Mater. 2005, 17, 2115.

[22] W. Lee, R. Ji, U. Gosele, K. Nielsch, Nature Mater. 2006, 5, 741.

[23] H. Masuda, K. Yada, A. Osaka, Jpn. J. Appl. Phys. 1998, 37, L1340. 